\title{
A New Approach of Electric Field Adoption for Germination Improvement
}

\author{
Waman Ziblaji Gandhare1, Mamta Samir Patwardhan² \\ ${ }^{1}$ Government College of Engineering, Amravati, Maharashtra state, India \\ ${ }^{2}$ Department of FSRE, Dr. A. S. College of Agricultural Engineering, MPKV, Ahmednagar, Maharashtra state, \\ India \\ Email: wz gandhare@yahoo.com, patmam@sify.com
}

Received December 2013

\begin{abstract}
Enhancement of tomato seed germination is one of the most important factors for developing a supply chain of increased demand. Tomato is one of the important cash crops in the world. To fulfill increased requirement, electric field adoption is the best alternative. The study was undertaken at MPKV, Rahuri for improvement in tomato seed germination. Three different approaches were utilized as electrostatic field, microwave and corona discharge method to treat tomato seeds. The comparative analysis revealed that adoption of electrostatic field application was simple as well as powerful method with significantly positive results. In electrostatic field, the optimal dosage was $2 \mathrm{kV} / \mathrm{mm}$ for 20 second interval to improve germination, root shoot length and seed vigor.
\end{abstract}

\section{Keywords}

Electrostatic Field; Microwave Field; Corona Discharge Treatment; Germination

\section{Introduction}

Experimental study of the effects of electricity on plant growth began in 1746. Early researchers discovered the application of electricity in agriculture for different purposes such as for seed treatment, seedling growth, plant growth, insect control and so on. Although their research aims were good, their apparatus, experimental designs and methods, process, dosage, amplitude of voltage, and the treatment time were not scientific so that they often got contradictory results [1].

The application of electricity, magnetism, monochrome light and sound can stimulate the growth of plants to a great extent. The energies are applied to the seeds, plants, soil or the water and nutrients. This technology termed as electro-culture, can protect plants from diseases, insects and frost. These methods can also reduce the requirements for fertilizer or pesticides [2].

It is well known that currents of electricity exist in the atmosphere. Clouds are charged and discharged. There is constant change of electricity from earth to air and from air to earth. The earth is the reservoir for all electricity. The electricity is the potent factor in the economy of nature and has more to do with the growth and developments of plants. Plant food is carried throughout the plant by means of the flow of sap, these currents circu- 
lates through all rootlets and centre as it were, in the stalk, carrying their tiny burdens of various elements and depositing them in the proper places. This phenomenon of sap circulation can be doubled due to electricity [3].

The several approaches of electricity were reviewed [4]. Morar [5] experimented with electrostatic field ranging 2 to $6 \mathrm{kV} / \mathrm{cm}$ with exposure time of 1 to $30 \mathrm{sec}$. for bean seeds. Huang [6] treated cucumber seeds with field strength of $1 \mathrm{kV}$ to $7 \mathrm{kV} / \mathrm{cm}$. Efe [7] conducted experiments with corona shocking instrument for cotton seeds. Pozeliene [8] processed rapeseeds with corona discharge field in the conveyer type electric separator. Zhou [9] designed new atmospheric plasma device, to explore approximate voltage of plasma treatment for tomato seeds. Aladjadjiyan [10] treated lentil seeds by using microwave of 2 - 45 GHz. frequency. More [11] utilized microwaves for sorghum.

Out of these all possibilities, it was felt that electrostatic field, microwave field and corona discharge methods were prominent. Hence a comparative study was undertaken to verify the effects of high voltage application for tomato seed treatment. Based on these pretreatments of seed before sowing, the study was planned.

\section{Experimental Procedure}

As described above, three methodologies were adopted for tomato seed treatment. Seeds of tomato $c v$. Dhanshree developed by MPKV, Rahuri were used for trials. Germination tests were conducted as per ISTA standards.

\subsection{Electrostatic Field Treatment}

The test cell consisted of two horizontal electrodes, connected to a fully adjustable ac high voltage supply of 0 to $5 \mathrm{kV}, 50 \mathrm{~Hz}$. The disks were covered with thin insulating films to avoid contact between the seeds and electrodes. Several laboratory tests were conducted to determine high-intensity electric field exposure causes any change in germination. The voltage gradient of $1 \mathrm{kV}, 2 \mathrm{kV}, 3 \mathrm{kV} / \mathrm{mm}$ with time duration of 10, 20, 30 seconds were finalized.

\subsection{Microwave Energy Treatment}

The influence of microwave irradiation on Tomato seeds has been investigated. A magnetron with frequency of radiation $2.45 \mathrm{GHz}$ and maximum output power $900 \mathrm{w}$ according to supplier data has been used as microwave source. Several laboratory tests were carried out and power levels as well as duration of irradiations were fixed as $90 \%, 70 \%, 60 \%$ of power and $10,20,30$ seconds for time.

\subsection{Corona Discharge Method}

Plasma has been used for seed mutation. Atmospheric plasma discharge equipment was used. It had two parallel high voltage electrodes. Seeds were put under atmospheric pressure plasma, the plasma would bring a mass electron, ion and ozone, and the mass electrons were faster. The ozone was the main component to react on tomato seed for mutation. Various trials were carried out and operating voltage levels as $2 \mathrm{kV}, 4 \mathrm{kV}$ and $6 \mathrm{kV}$ were fixed with time interval 15, 10, 5 second at high frequency of $15 \mathrm{kHz}$.

For these all methods, germination tests were carried out. For each method nine variable combinations of voltage and time were considered. One untreated seed lot was used as control. Each seed lot was of 50 seeds. Three replications were utilized for statistical analysis. Germination trials were carried out in seed germinator where temperature and humidity was maintained at $25^{\circ} \mathrm{C}$ at $80 \%$ relative humidity. Similarly same seeds were also sown in the plugs filled with soil having sufficient moisture well suited as open field conditions. Germination percentage was calculated as per standards. Additionally, root shoot length and seed vigor study was also completed.

\section{Results and Discussion}

After seeds were treated, germination trials were started immediately. The germination percentage were counted as first day count and final count on fourth and fourteenth day as per ISTA norms. Tables 1-3 show the changes in seed germination percentage due to adoption of different methods of electric field exposure.

\subsection{Germination Improvement Based on Electrostatic Field Exposure}

As per standards, the perti dishes were used for each lot with three replications. The electrostatic field exposure 
Table 1. Results of germination improvement due to electrostatic field application.

\begin{tabular}{ccccc}
\hline \multirow{2}{*}{ Treatment } & \multicolumn{3}{c}{ Germination (\%) } \\
\cline { 3 - 5 } & $1 \mathrm{kV}, 10 \mathrm{Sec}$ & 98 & $\mathrm{R}_{2}$ & $\mathrm{R}_{3}$ \\
\hline $\mathrm{V}_{1} \mathrm{~T}_{1}$ & $1 \mathrm{kV}, 20 \mathrm{Sec}$ & 98 & 100 & 98 \\
$\mathrm{~V}_{1} \mathrm{~T}_{2}$ & $1 \mathrm{kV}, 30 \mathrm{Sec}$ & 98 & 98 & 100 \\
$\mathrm{~V}_{1} \mathrm{~T}_{3}$ & $2 \mathrm{kV}, 10 \mathrm{Sec}$ & 100 & 98 & 98 \\
$\mathrm{~V}_{2} \mathrm{~T}_{1}$ & $2 \mathrm{kV}, 20 \mathrm{Sec}$ & 100 & 100 & 98 \\
$\mathrm{~V}_{2} \mathrm{~T}_{2}$ & $2 \mathrm{kV}, 30 \mathrm{Sec}$ & 100 & 98 & 100 \\
$\mathrm{~V}_{2} \mathrm{~T}_{3}$ & $3 \mathrm{kV}, 10 \mathrm{Sec}$ & 98 & 98 & 98 \\
$\mathrm{~V}_{3} \mathrm{~T}_{1}$ & $3 \mathrm{kV}, 20 \mathrm{Sec}$ & 98 & 100 & 98 \\
$\mathrm{~V}_{3} \mathrm{~T}_{2}$ & $3 \mathrm{kV}, 30 \mathrm{Sec}$ & 100 & 100 & 98 \\
$\mathrm{~V}_{3} \mathrm{~T}_{3}$ & 92 & 92 & 99 \\
& Control & &
\end{tabular}

Table 2. Results of germination improvement due to microwave field application.

\begin{tabular}{lrccc}
\hline & \multirow{2}{*}{ Treatment } & \multicolumn{3}{c}{ Germination (\%) } \\
\cline { 3 - 5 } & & $\mathrm{R}_{1}$ & $\mathrm{R}_{2}$ & $\mathrm{R}_{3}$ \\
\hline P1T1 & $90 \%, 10$ sec. & 100 & 98 & 98 \\
P1T2 & $90 \%, 20$ sec. & 100 & 100 & 98 \\
P1T3 & $90 \%, 30$ sec. & 100 & 98 & 98 \\
P2T1 & $70 \%, 10$ sec. & 98 & 98 & 98 \\
P2T2 & $70 \%, 20$ sec. & 100 & 100 & 99 \\
P2T3 & $70 \%, 30$ sec. & 98 & 98 & 98 \\
P3T1 & $60 \%, 10$ sec. & 96 & 98 & 98 \\
P3T2 & $60 \%, 20$ sec. & 98 & 98 & 98 \\
P3T3 & $60 \%, 30$ sec. & 98 & 94 & 98 \\
& Control & 92 & 92 & 92 \\
\hline
\end{tabular}

Table 3. Results of germination improvement due to corona field application.

\begin{tabular}{ccccc}
\hline & \multicolumn{3}{c}{ Treatment } & \multicolumn{2}{c}{ Germination (\%) } \\
\cline { 3 - 5 } & & $\mathrm{R}_{1}$ & $\mathrm{R}_{2}$ & $\mathrm{R}_{3}$ \\
\hline V1f1 & $2 \mathrm{kV}, 15 \mathrm{Sec}$ & 100 & 100 & 98 \\
V1f2 & $2 \mathrm{kV}, 10 \mathrm{Sec}$ & 98 & 100 & 98 \\
V1f3 & $2 \mathrm{kV}, 5 \mathrm{Sec}$ & 98 & 98 & 96 \\
V2f1 & $4 \mathrm{kV}, 15 \mathrm{Sec}$ & 96 & 96 & 94 \\
V2f2 & $4 \mathrm{kV}, 10 \mathrm{Sec}$ & 100 & 100 & 100 \\
V2f3 & $4 \mathrm{kV}, 5 \mathrm{Sec}$ & 96 & 96 & 96 \\
V3f1 & $6 \mathrm{kV}, 15 \mathrm{Sec}$ & 96 & 96 & 96 \\
V3f2 & $6 \mathrm{kV}, 10 \mathrm{Sec}$ & 96 & 98 & 96 \\
V3f3 & $6 \mathrm{kV}, 5 \mathrm{Sec}$ & 96 & 98 & 94 \\
& Control & 92 & 92 & 92 \\
\hline
\end{tabular}


apparatus was designed and developed for demonstration purpose. With reference to so many trials, treatment parameters were finalized. On fourteenth day, germination count was noted. Table 1 revealed that the treatment $\mathrm{V}_{2} \mathrm{~T}_{2}$ was significantly good. Basically all treated seeds showed better results.

\subsection{Germination Improvement based on Microwave Field Exposure}

Similar to electrostatic field exposure, another set up was arranged for microwave field treatment. For further large scale set up, different unit of industrial microwave set up was proposed for installation in process of seed treatment unit. The results were encouraging in comparison with untreated one. Table 2 recommended $\mathrm{P}_{2} \mathrm{~T}_{2}$ treatment of 70\% power level with 20 second time of application for enhancement.

\subsection{Germination Improvement based on Corona Discharge Field Exposure}

Alternative method of corona discharge field exposure was also tested for seed treatment before sowing in petri dishes. Based on prior trials, working high voltage level and speed based time setting combination were finalized. Table 3 represented results confirmed that there was positive effect on corona discharge field on seed germination process. The moderate voltage and speed was the best option for optimum results.

The development of root shoot for electrically treated tomato seeds was faster as in Figures 1-3.

This germination process was related to basic mechanism which explains stimulating effects of electric field exposure. Ozone generation by partial discharges between seeds and the activation of $\mathrm{OH}$ radicals under the action of the high-intensity electric field was assumed to be responsible for the intensification of the biological processes. The processes had been reported to be time dependent. The above described seed exposure processes were employed at three different high voltage levels. Laboratory tests showed that the germination energy of the treated seed samples increased as compared to untreated ones (Figure 1) for electrostatic field exposure.

\subsection{Some Common}

- Quotation marks are used, instead of a bold or italic

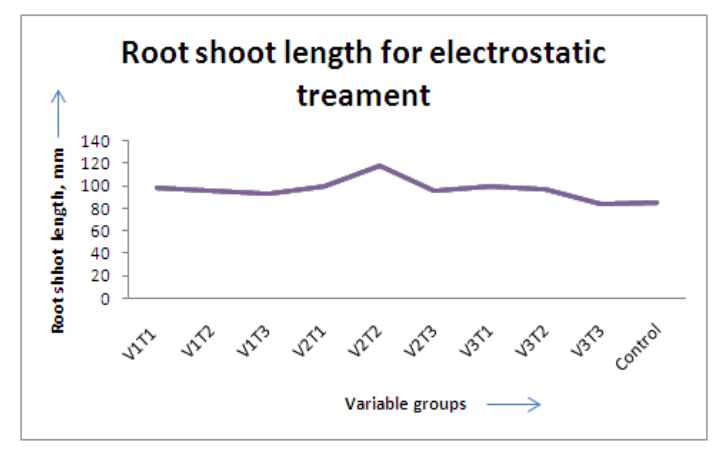

Figure 1. Graphical presentation for effect of electrostatic field on root shoot length.

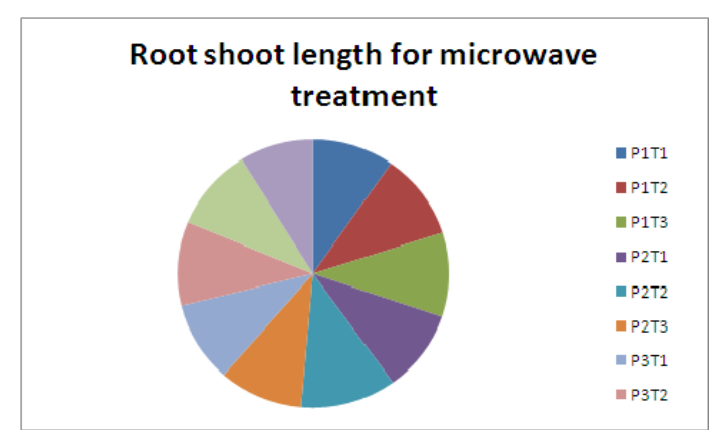

Figure 2. Graphical presentation for effect of microwave field on root shoot length. 


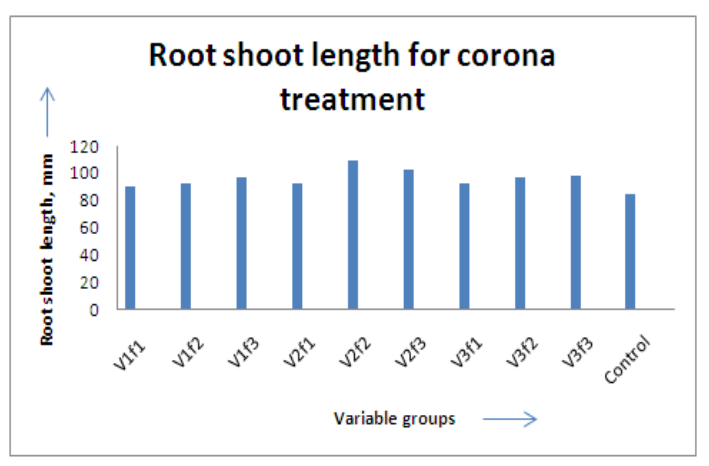

Figure 3. Graphical presentation for effect of corona field on root shoot length.

Ozone generation by partial discharges between seeds seems to be the main effective parameter to enhance the growth. Thus with adoption of electric field for seed treatment, the germination and seed vigor can be improved. Ultimately it results in maximum yield. The food production may be increased. As per review [3], this technique results in reduced fertilizer and pesticide requirement that will be the added advantage.

Comparative study reflects that the method of electrostatic field exposure was the best. It was found easy for adoption too. A simple circuit incorporated in this treatment may give advantage of cost effectiveness for commercial approach.

This will help rural development and create tremendous wealth in these areas. But still technology needs to go a long way in the process of research and development so that it can be made available at economical rates and the feasibility can be increased.

\section{Conclusions}

- The application of electrostatic field, microwave irradiation and corona discharge methods had a prominent impact on seed germination.

- The adoption of electrostatic field is most superior method for seed enhancement. Due to simplicity, this technique is suitable for commercialization.

- The voltage gradient of $2 \mathrm{kV} / \mathrm{mm}, 20$-second interval is the optimal value for best results.

- Better results are observed for older seed lots for improving germination count and seed vigor.

- In Indian scenario, there is a need to apply these methods to improve growth, yield and minimize the fertilizer/pesticides requirements.

\section{Acknowledgements}

The authors would like to thank Dr. R. D. Bansod, Head, Department of FSRE and Dr. P.A. Turbatmath, Associate Dean, Dr. A. S. CAE, MPKV, Rahuri for their valuable suggestions and inspiration. The authors acknowledge with thanks the fruitful discussions with Dr. R.S. Patil, Director of Research, MPKV, Rahuri.

\section{References}

[1] Gui, Z.-B., Piras, A., Qiao, L.-M., Gui, K. and Wang, B. (2013) Improving Germination of Seeds Soaked GA3 by Electrostatic Field Treatment. International Journal of Recent Technology and Engineering, 2, 133-136.

[2] Nelson, R.A. (2011) Electro-Culture. www.rexresearch.com

[3] Bailey, L.H. (2011) Cyclopedia of American Agriculture: Vol. II-Crops, 32-34. http://books.google.co.in

[4] Patwardhan, M.S. and Gandhare, W.Z. (2013) Effect of Electricity on Seed Germination. IEEMA Journal, 5, 88-92.

[5] Morar, R., Munteanu, R., Simion, E, Munteanu, I. and Dascalescu, L. (1999) Electrostatic Treatment of Bean Seeds. IEEE Transactions on Industry Applications, Vol. 35, 208-212. http://dx.doi.org/10.1109/28.740867

[6] Huang, R., Sukprakarn, S., Phavaphutanon, L., Juntakool, S. and Chaikul, C. (2006) Changes in Antioxidant Enzyme Activity, Lipid Perooxidation and Seedling Growth of Cucumber Seed Induced by Hydro Priming and Electric Field Treatments. Kasetsart Journal (Nature Science), 40, 825-834. 
[7] Efe, L., Mustalayev, S.A. and Killi P. (2004) Stimulative Effect of High Voltage Electrical Current on Earliness Yield and Fiber Quality of Cotton. Pakistan Journal of Biological Sciences, 7, 495-502.

[8] Pozeliene, A. and Lynikiene, S. (2009) The Treatment of Rape Seeds with the Help of Electrical Field. Agronomy Research, 7, 39-46.

[9] Zhou, Z., Huang, Y., Yang, S. and Chen, W. (2011) Introduction of a New Atmospheric Pressure Plasma Device and Application on Tomato Seeds. Agricultural Sciences, 2, 23-27. http://dx.doi.org/10.4236/as.2011.21004

[10] Aladjadjiyan, A. (2010) Effect of Microwave Irradiation on Seeds of Lentils. Romanian Journal of Biophysics, 20, 213-221.

[11] More, H.G., Magan, N. and Stenning, B.C. (1992) Effect of Microwave Heating on Sorghum \& Mycoflora of Sorghum grain. Journal of Stored Product Research, 28, 251-256. http://dx.doi.org/10.1016/0022-474X(92)90005-B 